\title{
Numerical Simulation Analysis of Model Simplification and Heat Transfer in Position Engineering
}

\author{
Yuan Liu1, a , Shunbo Liu2, b and Haiding Zhang 2, c \\ 1502 Faculty, Xi' an Institute of High Technology, Xi'an 710025, China \\ 2502 Faculty, Xi' an Institute of High Technology, Xi'an 710025, China \\ a1140509918@qq.com,b2864066508@qq.com, c295006978@qq.com
}

\begin{abstract}
In order to determine the processing capacity of the airflow and the air conditioning capacity of the position engineering, the heat transfer process of the air and the wall in the project is analyzed. The actual arch engineering is simplified into equal volume square and spherical engineering respectively. The physical mathematical model of underground heat transfer is proposed, and the initial conditions and boundary conditions are accorded with the engineering practice. The numerical simulation of the heat exchange and related parameters of the airflow and engineering wall is realized by FLUENT software. The paper analyzes and compares the errors of arched structure engineering and two kinds of simplified engineering, and draws the conclusion that it is feasible to simplify the project and simplify the engineering error.
\end{abstract}

Keywords: Position engineering, initial condition, numerical simulation

\section{Introduction}

Position works usually usually have low temperature, wet conditions. The heat transfer capacity of the underground wall is a key basic data for reasonably determining the capacity of the ventilation and air conditioning system. It is not only possible to adjust the air temperature by geothermal energy, but also provide an effective method for the study of airborne air tissue and load calculation of underground engineering, and improve the air conditioning system design. Air and underground engineering surrounding rock heat transfer numerical simulation, predecessors have done a lot of work, put forward the relevant calculation model and method [1-4], Guo Yi Chan air three-dimensional heat transfer model is simplified into one-dimensional heat transfer model, not considered The actual three-dimensional heat transfer of air [5]; the actual engineering model is often more complex, direct calculation is more difficult, the current research on the thermal engineering of underground engineering is the actual model is simplified into a relatively simple rule model, but not all The simplified method will bring more accurate results. Therefore, it is an important problem to study the feasibility and accuracy of the simplified model of underground engineering actual model.

\section{Physical model and its simplification}

The arched structure is usually composed of cave and surrounding rock. In this paper, the actual arch engineering is simplified into square engineering and 
spherical equation, and the simulation is carried out under the same working conditions. The length of the project is: length $\mathrm{L} 1=4 \mathrm{~m}$, width $\mathrm{b} 1=4 \mathrm{~m}$, height h1 $=3.2 \mathrm{~m}$, arch height $\mathrm{f} 1=1.2 \mathrm{~m}$, square project: length $\mathrm{L} 2=4 \mathrm{~m}$, width $\mathrm{b} 2=4 \mathrm{~m}$, high $\mathrm{h} 2=4 \mathrm{~m}, \mathrm{R}=2.48 \mathrm{~m}$, the project is surrounded by granite, arch engineering, square engineering and spherical engineering, respectively, as shown in Figure $1-1,1-2,1-3$.

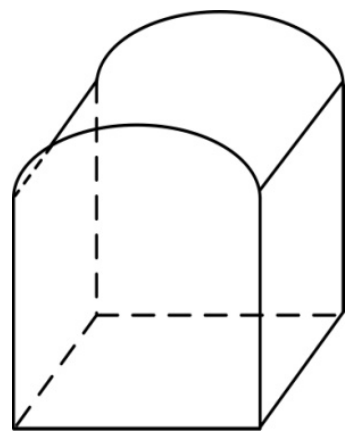

1-1 Schematic diagram of arch

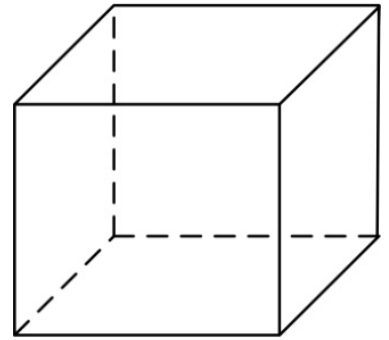

1-2 square engineering schematic diagram

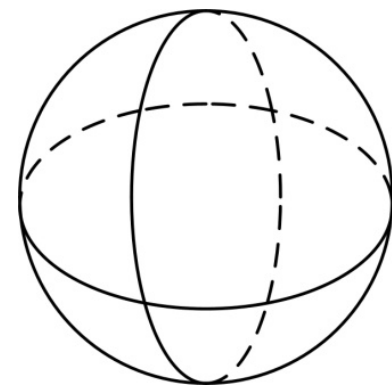

1-3 schematic engineering sphere

The thermal properties of the surrounding granites are: thermal conductivity $\lambda \mathrm{s}=2.04 \mathrm{~W} /\left(\mathrm{m} \cdot{ }^{\circ} \mathrm{C}\right), \rho=2700 \mathrm{~kg} / \mathrm{m}^{3}$, specific heat $\mathrm{c}=824 \mathrm{~J} /\left(\mathrm{kg} \bullet{ }^{\circ} \mathrm{C}\right)$, where the temperature of the formation is perennial at $12^{\circ} \mathrm{C}$.

The nature of the surrounding rock, the geological structure, and the distribution of groundwater will have a certain effect on the heat exchange of the duct. Easy to study, the actual model of the appropriate simplified, as follows:

(1) the air is often incompressible Newtonian fluid, and the same conditions of wind speed stability;

(2) the texture of the rock is uniform and isotropic, and the thermophysical properties are constant.

(3) the duct is buried in the constant temperature below the initial temperature is equal to the depth of the surrounding rock annual average temperature;

(4) the air inside the duct to convection heat, ignoring the air and wall radiation;

(5) Distance from the center of the duct is far enough to keep the temperature of the surrounding rock stable, which is not affected by air heat transfer in the duct.

\section{Mathematical model}

In the three-dimensional Cartesian coordinate system, it is assumed that the velocity components of the velocity vector $U$ in $x, y$ and $z$ are $u, v, w$, the fluid density is $\rho$, the pressure is $p$, and the time is t. Apply the conservation law to any control element volume dxdydz to write the conservation control equation ${ }^{[7]}$.

\section{1 the conservation of mass equation}

$$
\frac{\partial \rho}{\partial t}+\operatorname{div}(\rho U)=0
$$

\section{2 momentum conservation equation}

U-momentum conservation equation 


$$
\frac{\partial(\rho u)}{\partial t}+\operatorname{div}(\rho u \boldsymbol{U})=\operatorname{div}(\mu \operatorname{grad} u)+S_{u}-\frac{\partial p}{\partial x}
$$

V-momentum conservation equation

$$
\frac{\partial(\rho v)}{\partial t}+\operatorname{div}(\rho v \boldsymbol{U})=\operatorname{div}(\mu \operatorname{grad} v)+S_{v}-\frac{\partial p}{\partial y}
$$

$\mathrm{W}$-momentum conservation equation

$$
\frac{\partial(\rho w)}{\partial t}+\operatorname{div}(\rho w \boldsymbol{U})=\operatorname{div}(\mu \operatorname{grad} w)+S_{w}-\frac{\partial p}{\partial z}
$$

Among them, Su, Sv, Sw is the generalized source term of each momentum equation, and $\mu$ is the dynamic viscosity of the fluid.

\section{3 energy conservation equation}

$$
\frac{\partial(\rho T)}{\partial t}+\operatorname{div}(\rho v T)=\operatorname{div}\left(\frac{k}{c_{p}} \operatorname{grad} T\right)+\frac{S_{T}}{c_{p}}
$$

Where $\mathrm{cp}$ is the specific heat capacity, $\mathrm{T}$ is the temperature, $\mathrm{k}$ is the fluid heat transfer coefficient, and ST is the viscous dissipation term.

\section{Numerical simulation and result analysis}

\section{1 simulation calculation}

This paper uses the most widely used CFD software FLUENT for numerical simulation. Application of ICEM in the Cartesian coordinate system, the establishment of duct geometry and the grid.

Import the grid file into the FLUENT14.5 3D double solver, check the grid, make the relevant settings: Define the non-steady state solution, turn on the energy equation, the air duct inner wall initial temperature and the far field boundary temperature for the buried depth stratigraphic annual average The temperature is $t 0=12^{\circ} \mathrm{C}$, the wall with the air contact is the third kind of boundary condition: the constant temperature $t$ $=26{ }^{\circ} \mathrm{C}$, the convective heat transfer coefficient $\mathrm{h}=5.82 \mathrm{~m}$, the other boundary is adiabatic; the SIMPLE algorithm is used to set the energy equation The criterion is $10^{-6}$, the convergence criterion of other flow equations is $10^{-3}$, and the other settings are default, and the calculation is started after initialization.

The values of the temperature field of the cross section are shown in Fig. 3-3, 3-4, 3-5. The values of $\mathrm{Y}$ and $\mathrm{Z}$ represent the width and height of the duct respectively. The curve is a temperature contour, which is the value on the curve in $\mathrm{K}$. It can be seen from the figure, the engineering section temperature distribution is not uniform, near the wall temperature gradient. 


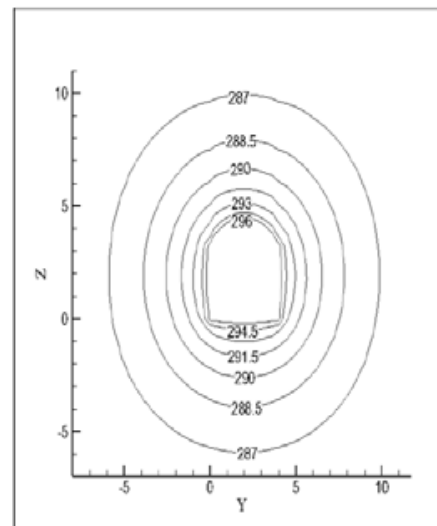

Figure 3-3

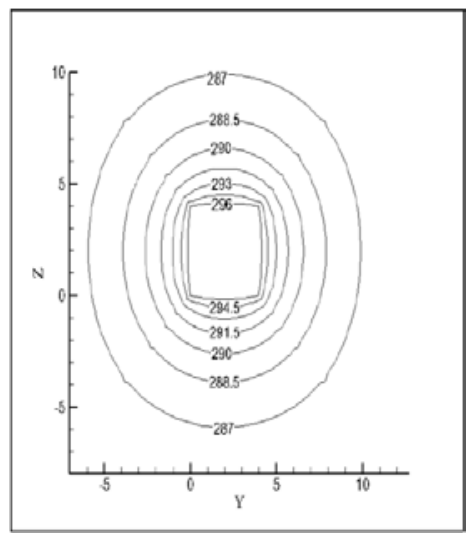

Figure 3-4

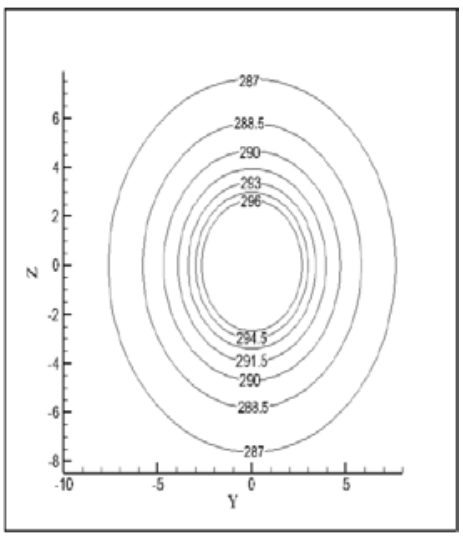

Figure 3-5

Figure 3-3 Arched project section temperature profile

Figure 3-4 section of the cross section of the temperature profile

Figure 3-5 Spherical section temperature profile

The average heat flux of the wall is the time and the ordinate is the average heat flow. As shown in Figure 3-6, 3-7, the abscissa is the time and the ordinate is the average heat flow. It can be seen from the figure, with the heat transfer, the heat transfer strength gradually reduced, and finally tend to be constant, in line with the actual situation. It can be seen that the curve of cube and arched works is consistent with the trend of time curve, and the coincidence degree is high.Compared with the arch engineering, the relative error of the average heat flow is less than $2 \%$, and the relative error of the average heat flow of the spherical engineering wall is more than $10 \%$, and the error is larger. It is feasible and accurate to simplify the arched project into the cube project, and the arch engineering is simplified to the ball body engineering error, which should not be used.

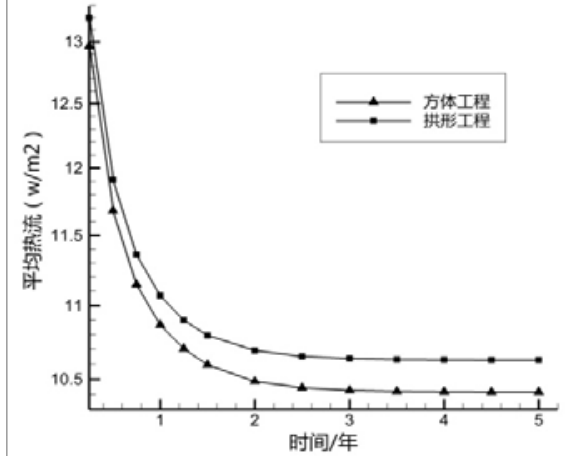

Figure 3-6

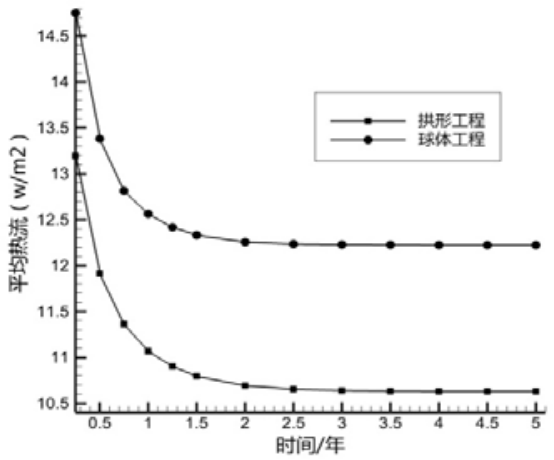

Figure 3-7

Figure 3-6 cube and arched works of the average wall heat flow with time

Figure 3-7 Spherical engineering and arch engineering wall wall average heat flow with time

\section{2 verification of simulation methods}

In order to verify the reliability of the numerical calculation model, the spherical model is calculated according to the method provided in Chapter 4 of the "Theory and Application of Thermal Engineering for Underground Engineering" (Mao Jinfeng, Han $\mathrm{Xu}$ ). Table 3-1 shows the comparison of the mean wall heat flow calculated by 
the numerical simulation and the theoretical calculation.

Table 3-1 Comparison of numerical simulation and theoretical calculation

\begin{tabular}{|c|c|c|c|c|}
\hline \multicolumn{2}{|c|}{ Time } & A month & Six months & A year \\
\hline Average heat & $\begin{array}{c}\text { Simulation } \\
\text { calculation }\end{array}$ & 18.05 & 13.40 & 12.61 \\
\cline { 2 - 5 } flow (w/m2) & $\begin{array}{c}\text { Theoretical } \\
\text { calculation }\end{array}$ & 17.98 & 13.38 & 12.56 \\
\hline
\end{tabular}

It can be seen from Table 3-1 that the numerical simulation results are very close to the theoretical calculation. On the whole, the results of the two calculations show a good consistency, which shows that the numerical calculation method proposed in this paper is reliable and can be used for wall heat flux prediction.

\section{Conclusion}

The analysis of the heat transfer process of the wall of the project is carried out, and the arch engineering is simplified into the regular cube engineering and the spherical engineering respectively. Based on FLUENT, the numerical simulation is carried out. The temperature profile of the cross section of the simplified engineering and the actual project is obtained, and the time variation curve is simplified with each other. It is feasible to simplify the calculation of the arch engineering to simplify the numerical simulation of the arch engineering under the condition of this article. It is feasible to simplify the calculation of the arched project into the cube project.

\section{References}

[1] Wen Jianjun, Li Angui.Study on Simulation of Ventilation and Heat Transfer Performance of Dam Corridors [J] .Power and Hydropower Engineering, 2010, 28 (7): 98-101.

[2] YANG Wei, SUN Yue, XUE Sihao.Numerical simulation of heat transfer between surrounding rock and air in ventilation tunnel [J] .Journal of Heilongjiang Institute of Science and Technology, 2010, 20 (4): 256-259.

[3] Misra R, Bansal V, Agrawal G D, et al. CFD analysis based parametric study of derating factor for Earth Air Tunnel Heat Exchanger [J]. Applied Energy, 103 (2013): 266-277.

[4] Misra R,Bansal V,Agrawal G D,et al Transient Analation of Deratinysis Based Determing Factor for Earth Air Tunnel Heat Exchanger in summer[J].Energy and Buildings, 2013,(58):103-110.

[5] GUO Yi-Chan.Study on General Calculation Model of Airflow Parameters in Underground Engineering Airway [J]. Building Thermal Ventilating \& Air Conditioning, 2011,30 (1): 59-62.

[6] Shu Mingjun. Deep air duct wet air condensation numerical simulation [J]. Building Energy Conservation, 2015,43 (2): 9-12.

[7] Tang Jia Peng. FLUENT14.0 Super Learning Manual [M]. Beijing: People's Posts and Telecommunications Press, 2013: 15-35.

[8] ANSYS Inc. ANSYS Help, ANSYS Inc, 2013: 56-60.

[9] SHI Ming-jun.Experiment calculation of air heat and moisture transfer in deep underground air duct [J]. Journal of the Second Artillery Engineering University,2014.28(4)55-59 